W. Moalla ${ }^{1}$

G. Dupont ${ }^{2}$

S. Berthoin²

S. Ahmaidi ${ }^{1}$

\section{Respiratory Muscle Deoxygenation and Ventilatory Threshold Assessments Using Near Infrared Spectroscopy in Children}

ing exercise, the respiratory muscles deoxygenated as the exercise intensity increased. $\mathrm{StO}_{2}$ decrease progressively until an abrupt decrease was observed. No significant differences were observed between cardiorespiratory variables corresponding either to $\mathrm{VT}_{\mathrm{V} \text {-slope }}$ or to $\mathrm{VT}_{\text {nirs }}$. The two methods showed a good agreement (data were inside the $95 \%$ confidence interval). Likewise, a significant relationship was found between $\mathrm{VT}_{\mathrm{V} \text {-slope }}$ and $\mathrm{VT}_{\text {nirs }}$ for each parameter measured ( $\mathrm{r}=0.87$ to $0.94, \mathrm{p}<0.001$ ). We concluded that respiratory muscles deoxygenate during incremental exercise in children and that ventilatory threshold could be determined by NIRS.

\section{Key words}

NIRS · incremental exercise test · threshold determination · rib cage muscles

\section{Introduction}

Evaluation of physiological responses and assessment of exercise tolerance have usually been focused on the measurement of peak oxygen uptake $\left(\dot{\mathrm{V}}_{2 \max }\right)[11,30]$. Nevertheless, peak performance is more dependent on the subjects' motivation than submaximal performance, especially in children $[1,14]$. The common measurement of submaximal intensity is the determination of ventilatory threshold (VT) [17,22]. VT is defined as "the exercise intensity at which the increase in ventilation becomes disproportional to the increase in power output during an incremental ex- ercise test" [32]. At this point, the muscle requirement for oxygen begins to exceed that provided by the cardiovascular system. Consequently, lactate accumulates and acidosis, hyperventilation, and impaired exercise capacity are induced $[17,27]$. Wasserman et al. [36] explained accumulation of lactates by altered oxygen kinetics, hence tissue hypoxia. Various methods of determining VT have previously been used; ventilatory equivalents, excess $\mathrm{CO}_{2}$ production, lactate kinetics, etc. However, the simplest and the most common method used is the V-slope method [4] which is based on the determination of the nonlinear point of 
increase in slope of carbon dioxide production $\left(\dot{\mathrm{VCO}}_{2}\right)$ versus oxygen uptake $\left(\mathrm{V}_{2}\right)$ during incremental exercise.

The physiological changes from VT as lactate accumulation, metabolic acidosis, impaired muscle contraction, hyperventilation, altered oxygen kinetics [27] take place in peripheral muscles, but also in respiratory muscles whose work increases by several mechanisms [2]. In fact, the decrease in oxygen transport and ATP generation to the respiratory muscles during exercise has been described as the important causative mechanism in muscle fatigue because of lactic acid accumulation [16]. Thus, respiratory muscle function depends directly upon the ability to deliver an adequate supply of oxygen and substrates to support contractile activity [20].

Near infrared spectroscopy (NIRS) is a noninvasive and continuous method that allows the monitoring of oxygenation and blood volume in muscular tissue. Application, theoretical basis, advantages, and limitations of NIRS have been widely documented $[5,23,25]$. NIRS has often been used to evaluate peripheral muscle, especially the vastus lateralis. To the best of our knowledge, only two studies were interested in the respiratory muscles to assess deoxygenation [24,33]. Moreover, no study in the literature has employed NIRS in the measurements of oxygenation in children.

Because respiratory muscles contribute to exercise limitation and because oxygenation depends on the balance between oxygen consumption and oxygen supply [3], we hypothesized that: firstly, respiratory muscles deoxygenate during incremental cardiopulmonary exercise; secondly, NIRS could be used as an additional tool to assess respiratory muscles and to determine VT.

\section{Materials and Methods}

\section{Subjects}

Fourteen healthy boys (age, $12.8 \pm 1.4 \mathrm{yr}$; height, $155.1 \pm 8.7$; weight, $46.4 \pm 7.7 \mathrm{~kg}$ ) participated in this study. All subjects practiced recreational sports and physical activity only at school. The children and their parents signed a written informed consent in accordance with the ethical standards of the Helsinki Declaration of 1975.

\section{Lung function testing}

Measurements of pulmonary function were performed on a spirometer (Master Lab, Jaeger, Germany). The forced expiratory volume in 1 second $\left(\mathrm{FEV}_{1}\right)$, the forced vital capacity (FVC), and the total lung capacity (TLC) were determined. Results were expressed as absolute values and as percentage of predicted reference values (\%pred) according to Quanjer et al. [28]. The FEV1/FVC ratio was then calculated.

\section{Exercise testing protocol}

Each subject underwent an incremental exercise test with a constant pedalling cadence of 60 revolutions/min (rpm) on an electromagnetically braked cycle ergometer (Jaeger Ergoline, ER800, Germany). The increase in workload was individualized and was calculated according to the Wasserman norms as a function of sex, weight, and age of each child [37]. The test involved four consecutive periods: (1) a 3-min rest period, (2) a 2-min period of warm-up against a workload corresponding to $20 \%$ of the theoretical maximal power output, (3) an 8-to 12-min exercise period with increases in the workload every minute until exhaustion, and (4) a recovery period. Standardized encouragements were given to the children to develop their maximum effort. Tests were considered maximal when at least three of the following criteria were achieved: (1) stabilization of $\mathrm{VO}_{2}$ despite a further increase in workload, (2) the respiratory exchange ratio (RER) greater than 1.1, (3) a maximal heart rate (HR) close to the predicted maximal HR; and (4) the inability to maintain the pedalling speed $(60 \mathrm{rpm})$.

\section{Pulmonary gas exchange}

Pulmonary ventilation $(\dot{\mathrm{V} E}), \dot{\mathrm{V}} \mathrm{O}_{2}$, and $\dot{\mathrm{V}} \mathrm{CO}_{2}$ were determined breath-by-breath by means of a respiratory gas analyzing system (MGA 1100 Medical, Marquette Electronics, USA). The subjects wore a nose clip and breathed through a mouthpiece (Hans-Rudolph). Before each test, gas analyzers were calibrated with known reference gases $\left(12 \% \mathrm{O}_{2}, 5 \% \mathrm{CO}_{2}\right.$, and $\left.83 \% \mathrm{~N}_{2}\right)$. The $\mathrm{HR}$ was monitored through the test and recorded continuously by electrocardiogram (12 SL Program, Marquette Electronics, USA).

\section{NIRS measurements}

The changes in respiratory muscle saturation $\left(\mathrm{StO}_{2}\right)$ were evaluated by NIRS (Runman, NIM, Philadelphia) consisting of a probe and a main unit. The probe, molded in elastic black silicone rubber, has a photodetector in the center and two light-emitting diodes (wavelengths of 760 and $850 \mathrm{~nm}$ ) on either side. The distance between diodes and photodetectors was $3 \mathrm{~cm}$ from each other. The depth of penetration of near infrared light is approximately equal to half the distance between light source and detector, i.e., $1.5 \mathrm{~cm}$ [25]. NIRS measurement is based on the relative tissue transparency for light in the near infrared region and on the $\mathrm{O}_{2}$-dependent absorption changes of hemoglobin ( $\left.\mathrm{Hb}\right)$ and myoglobin (Mb). However, it has been reported that the major signal from NIRS comes from $\mathrm{Hb}$ [23]. The values obtained reflect the balance between oxygen consumption and oxygen supply [26]. Changes in muscle oxygen saturation were estimated according to the difference in the two wavelengths $(760 \mathrm{~nm}-$ $850 \mathrm{~nm})$.

To record the NIRS signal, the probe was placed on the sixth intercostal space, at the anterior axillary line over the serratus anterior muscle as described by Mancini et al. [24] and Terakado et al. [33]. Concomitantly to the diaphragm, this superficial muscle serves as an accessory inspiratory muscle during ventilation to elevate ribs. A permanent marker was used on the skin to identify the location where the probe facing the muscle was placed, in order to ensure that it was invariant and was not displaced. A tape of clear plastic was placed around the probe to protect the photodetector from sweat and moisture and secured by straps and adhesive tape. In addition, an elasticised cloth was used around the chest to avoid movement of the probe. This preparation essentially prevented any probe movement relative to the skin surface. The data was displayed continuously on a monitor in real time and stored for further analysis.

After installing the subject on the ergocycle and prior to the test protocol, the NIRS was calibrated at $760 \mathrm{~nm}$ and $850 \mathrm{~nm}$ accord- 
ing to the manufacturer's instructions and specifications. Calibration was repeated before each test for each subject until the NIRS baseline value was obtained. The signal measured by NIRS indicates only qualitative data. Previous investigations have often employed arterial occlusion as a physiological scale to determine the level of oxygenation $[3,23,26]$. However, this method cannot be applied in the case of respiratory muscles. We therefore used the method described by Belardinelli et al. [5]; for changes in $\mathrm{StO}_{2}$, the lowest value obtained during incremental exercise test was taken as the minimum saturation, $0 \%$, whereas the maximal value recorded during recovery was taken as maximal saturation, $100 \%$ (maximal hyperemia); thus, $\mathrm{StO}_{2}$ values were expressed according to this scale.

\section{Determination of the ventilatory threshold}

After completion of each incremental test, the ventilatory threshold (VT) was determined for each subject using the Vslope method $\left(\mathrm{VT}_{\mathrm{V} \text {-slope }}\right)$ described by Beaver et al. [4]. This method involves the behaviour analysis of $\dot{\mathrm{V}} \mathrm{CO}_{2}$ as a function of $\dot{\mathrm{VO}}_{2}$ during exercise. VT corresponds to the breakpoint of the linearity of the curve $\dot{\mathrm{V}} \mathrm{CO}_{2}$ versus $\dot{\mathrm{VO}}_{2}$ (Fig. 1 a). Likewise, VT was determined by NIRS ( $\left.\mathrm{VT}_{\text {nirs }}\right)$ as the intensity at which an accelerated fall in tissue oxygenation was observed. This intensity is represented on the graph by the point of nonlinear decrease in oxygen saturation versus $\dot{\mathrm{VO}}_{2}$ (a breakpoint of the linearity of the curve also) (Fig. $1 \mathbf{b}$ ). These two points of $\mathrm{VT}_{\mathrm{V} \text {-slope }}$ and $\mathrm{VT}_{\text {nirs }}$ were determined randomly from graph visually on the computer by two experienced investigators having no prior knowledge of any results or subject identities. In the rare cases of disagreement, a third person was used to establish a consensual determination. Similarly, in order to reflect mechanical load of respiratory muscles, a similar breakpoint was observed when we plotted $\mathrm{StO}_{2}$ as a function of $\dot{V} E$ (Fig. 1 c).

\section{Data analysis}

$\mathrm{StO}_{2}$ and cardiorespiratory responses $\left(\mathrm{HR}, \dot{\mathrm{V} O}{ }_{2}, \dot{\mathrm{V}} \mathrm{CO}_{2}\right.$, and $\left.\dot{\mathrm{VE}}\right)$ were examined every minute at each stage. These variables were also determined separately at $\mathrm{VT}$ as detected by the $\mathrm{VT}_{\mathrm{V} \text {-slope }}$ and $\mathrm{VT}_{\text {nirs }}$ methods. For reliability and validation, Bland-Altman [8] plots were used to show the agreement between the two methods ( $\mathrm{VT}_{\mathrm{V} \text {-slope }}$ and $\mathrm{VT}_{\text {nirs }}$ ) for each parameter by evaluating their mean differences against their average. In addition, a one-way ANOVA was done to compare the data of cardiorespiratory responses, $\mathrm{StO}_{2}$, and power output at VT as detected by both methods. An a posteriori Fisher's procedure for learning systems design (PLSD) test was used when the F-ANOVA ratio was significant. A linear regression analysis was performed to determine relationships between $\mathrm{VT}_{\mathrm{V} \text {-slope }}$ and $\mathrm{VT}_{\text {nirs }}$ for each parameter. Statistical analyses were done using statistical software (StatView, SAS Institute, and MedCalc 7.2). All data are reported as means and standard deviation $( \pm S D)$. The level of significance was fixed at $\mathrm{p}<0.05$.

\section{Results}

The mean and standard deviation of anthropometric characteristics, spirometric parameters, as well as cardiorespiratory responses and the power output at peak exercise are presented in Table 1. Pulmonary function was normal and no restrictive or ob-
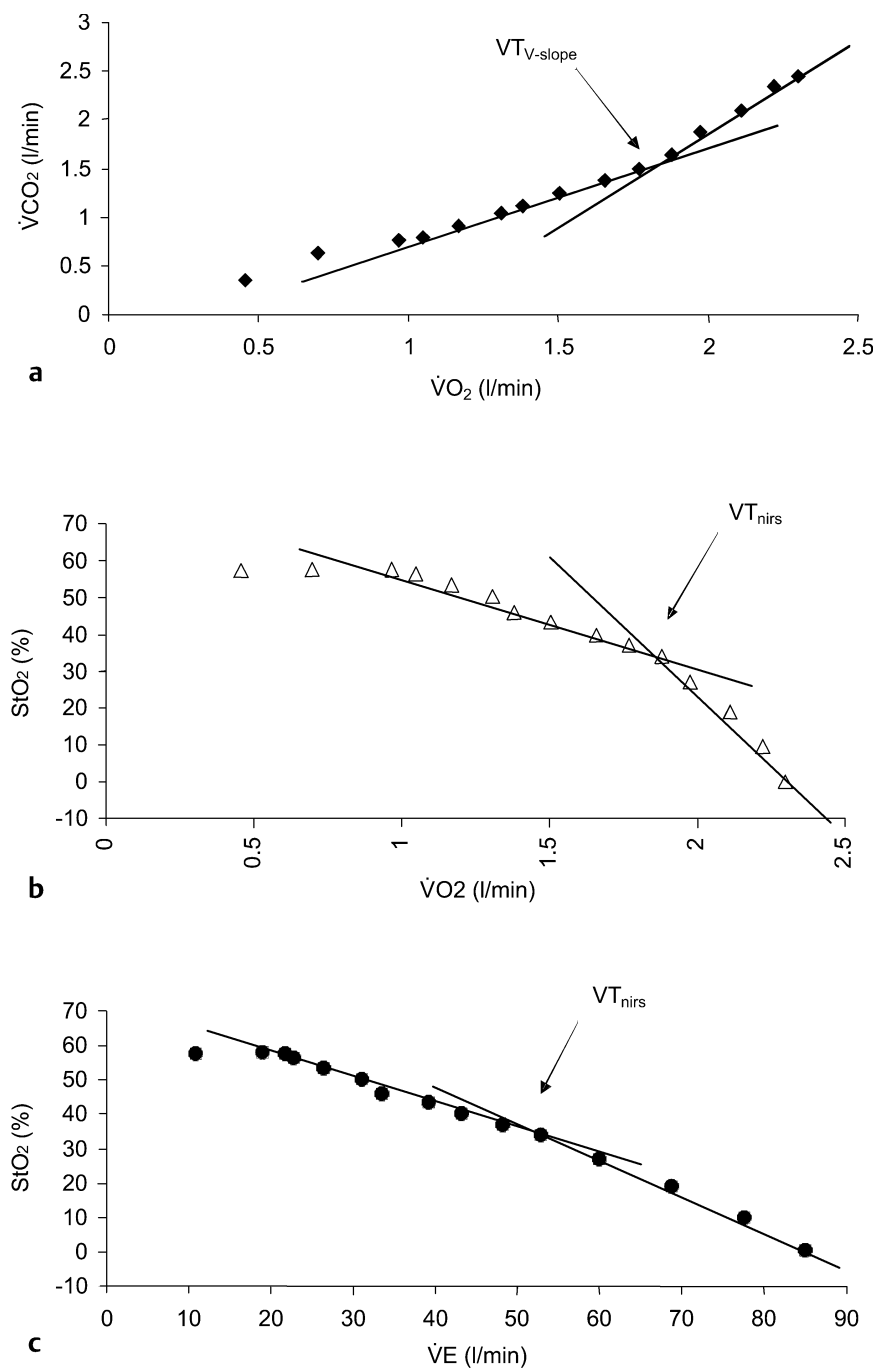

Fig. 1 a to $\mathbf{c}$ Typical example of the VT determination for one subject by $\mathrm{VT}_{\mathrm{V} \text {-slope }}$ (a upper graph), and $\mathrm{VT}_{\text {nirs }}$ (b middle graph). The lower graph (c) showed $\mathrm{StO}_{2}$ as a function of $\dot{V}$ which reflects mechanical load of the respiratory muscles.

structive syndrome was observed. All exercise tests performed by children conformed to criteria for maximal effort, except for two subjects stopping the test prematurely; thus we excluded them from study.

\section{Oxygenation changes}

A typical trace of $\mathrm{StO}_{2}$ during incremental exercise for one subject is given in Fig. 2. After a rest period, a slight increase in the NIRS signal during the warm-up period was observed. Thereafter, $\mathrm{StO}_{2}$ decreases progressively until a rapid fall and abrupt decrease of the oxygenation graph was observed. This breakpoint in the curve linearity corresponds to $\mathrm{VT}_{\text {nirs }}$. During recovery, a fast increase in $\mathrm{StO}_{2}$ which got above the resting value (hyperemia phase) was noted.

Relationship between $\mathrm{VT}_{\mathrm{V} \text {-slope }}$ and $\mathrm{VT}_{\text {nirs }}$

To validate the detection of VT by NIRS on the respiratory muscle we have assessed the relationship and the agreement between the $\mathrm{VT}_{\mathrm{V} \text {-slope }}$ and $\mathrm{VT}_{\text {nirs }}$ methods. The comparisons between parameters at VT detected by these methods are listed in Table 
Table 1 Anthropometric and spirometric parameters, and peak exercise results in children

\begin{tabular}{|c|c|c|}
\hline Subjects $(n=12)$ & & Value \\
\hline \multicolumn{3}{|l|}{ Anthropometric } \\
\hline - age & (yr) & $12.8 \pm 1.4$ \\
\hline - height & $(\mathrm{cm})$ & $155.1 \pm 8.7$ \\
\hline - weight & $(\mathrm{kg})$ & $46.4 \pm 7.7$ \\
\hline - BMI & $\left(\mathrm{kg} / \mathrm{m}^{2}\right)$ & $19.1 \pm 1.9$ \\
\hline \multicolumn{3}{|l|}{ Spirometric } \\
\hline \multirow[t]{2}{*}{ - FEV1 } & (I) & $2.69 \pm 0.43$ \\
\hline & (\%pred) & $100.05 \pm 14.28$ \\
\hline \multirow[t]{2}{*}{$-F V C$} & (l) & $3.21 \pm 0.55$ \\
\hline & (\%pred) & $93.01 \pm 13.52$ \\
\hline \multirow[t]{2}{*}{$-T L C$} & (I) & $4.25 \pm 0.61$ \\
\hline & (\%pred) & $90.56 \pm 13.06$ \\
\hline - FEV1/FVC ratio & & $1.04 \pm 0.16$ \\
\hline$-M V V$ & $(1 / \min )$ & $107.47 \pm 17.35$ \\
\hline \multicolumn{3}{|l|}{ Peak exercise } \\
\hline - power output & $(\mathrm{W})$ & $156.60 \pm 27.8$ \\
\hline \multirow[t]{2}{*}{$-\dot{V} O_{2 \max }$} & $(\mathrm{ml} / \mathrm{min} / \mathrm{kg})$ & $47.50 \pm 6.3$ \\
\hline & $(1 / \min )$ & $2.20 \pm 0.46$ \\
\hline$-\dot{V} \mathrm{CO}_{2 \max }$ & $(1 / \mathrm{min})$ & $2.37 \pm 0.46$ \\
\hline$-\dot{V} E_{\max }$ & $(1 / \min )$ & $76.40 \pm 12.2$ \\
\hline$-H R_{\max }$ & (beats/min) & $196.0 \pm 11$ \\
\hline
\end{tabular}

* Values are means \pm SD. BMI: body mass index; FEV1: forced expiratory volume in 1 second; FVC: forced vital capacity; TLC: total lung capacity; \%pred: percentages of predicted values

2. No significant differences were observed between parameters determined by both $\mathrm{VT}_{\mathrm{V} \text {-slope }}$ and $\mathrm{VT}_{\text {nirs }}(\mathrm{p}>0.05)$.

Analysis of linear regression between $\mathrm{VT}_{\mathrm{V} \text {-slope }}$ and $\mathrm{VT}_{\text {nirs }}$ for each parameter is shown in Fig. 3 (left panels). We found a strong positive correlation between the two methods $(\mathrm{p}<0.001)$ for all variables. Correlation coefficients for $\dot{\mathrm{V}} \mathrm{O}_{2}, \dot{\mathrm{V}} \mathrm{CO}_{2}$, and $\dot{\mathrm{VE}}$ were $r=0.93(p<0.0001), r=0.94(p<0.001)$, and $r=0.87(p<0.002)$, respectively. The correlation coefficients for $\mathrm{StO}_{2}$ and power out-
Table 2 Comparison between parameters at ventilatory threshold detected by both NIRS and V-slope

\begin{tabular}{|c|c|c|c|c|}
\hline \multicolumn{2}{|c|}{ Parameters } & \multirow{2}{*}{$\begin{array}{l}V T_{\text {nirs }} \\
\qquad 3.4 \pm 7.0\end{array}$} & \multirow{2}{*}{$\begin{array}{l}V T_{V-\text {-Slope }} \\
40.5 \pm 8.5\end{array}$} & \multirow{2}{*}{$\begin{array}{l}\text { p-value } \\
\text { (NS) }\end{array}$} \\
\hline$\dot{V E}$ & $(1 / \min )$ & & & \\
\hline & (\% of max) & $56.4 \pm 11.1$ & $52.2 \pm 10.7$ & \\
\hline \multirow[t]{2}{*}{$\mathrm{VO}_{2}$} & $(\mathrm{ml} / \mathrm{min} / \mathrm{kg})$ & $34.8 \pm 6.2$ & $33.4 \pm 6.7$ & (NS) \\
\hline & (\% of max) & $73.8 \pm 6.9$ & $69.7 \pm 6.8$ & \\
\hline \multirow[t]{2}{*}{$\dot{\mathrm{V}} \mathrm{CO}_{2}$} & (I/min) & $1.48 \pm 0.32$ & $1.38 \pm 0.39$ & (NS) \\
\hline & (\% of max) & $62.6 \pm 7.8$ & $57.6 \pm 7.2$ & \\
\hline \multicolumn{2}{|c|}{ Power output (W) } & $103.7 \pm 21.1$ & $96.6 \pm 27.6$ & (NS) \\
\hline \multicolumn{2}{|c|}{ HR (beats/min) } & $153.0 \pm 10$ & $147.0 \pm 4$ & (NS) \\
\hline \multicolumn{2}{|c|}{$\mathrm{StO}_{2}(\%)$} & $36.3 \pm 7.4$ & $37.8 \pm 7.1$ & (NS) \\
\hline
\end{tabular}

put were $r=0.94(p<0.0001)$ and $r=0.89(p<0.0001)$, respectively. The data detected by both methods were sometimes similar; for this reason, some values were superimposed on the graph, and the number of points is different than 12 (number of the subjects interpreted).

Fig. 3 (right panels) contains the Bland-Altman plots illustrating the mean differences $( \pm 1.96 \mathrm{SD})$ against the average value obtained by both $\mathrm{VT}_{\mathrm{V} \text {-slope }}$ and $\mathrm{VT}_{\text {nirs }}$ for $\dot{\mathrm{VO}}_{2}, \dot{\mathrm{V}} \mathrm{CO}_{2}$, and $\dot{\mathrm{V}}$. Overall, the difference in scores was within $95 \%$ of the confidence interval, showing that both methods agree closely. The $95 \%$ limits of agreement were therefore from -0.12 to $0.24 \mathrm{l} / \mathrm{min},-0.18$ to $0.38 \mathrm{l} / \mathrm{min}$, and -5.2 to $11.2 \mathrm{l} / \mathrm{min}$ for $\dot{\mathrm{VO}}_{2}, \dot{\mathrm{V}} \mathrm{CO}_{2}$, and $\dot{\mathrm{VE}}$, respectively.

\section{Discussion}

This study was performed to assess respiratory muscle oxygenation and to validate the use of NIRS as an additional method for the detection of VT in children. Two major findings were observed. Firstly, the respiratory muscles revealed by NIRS deoxygenate during incremental exercise in children; secondly, com-

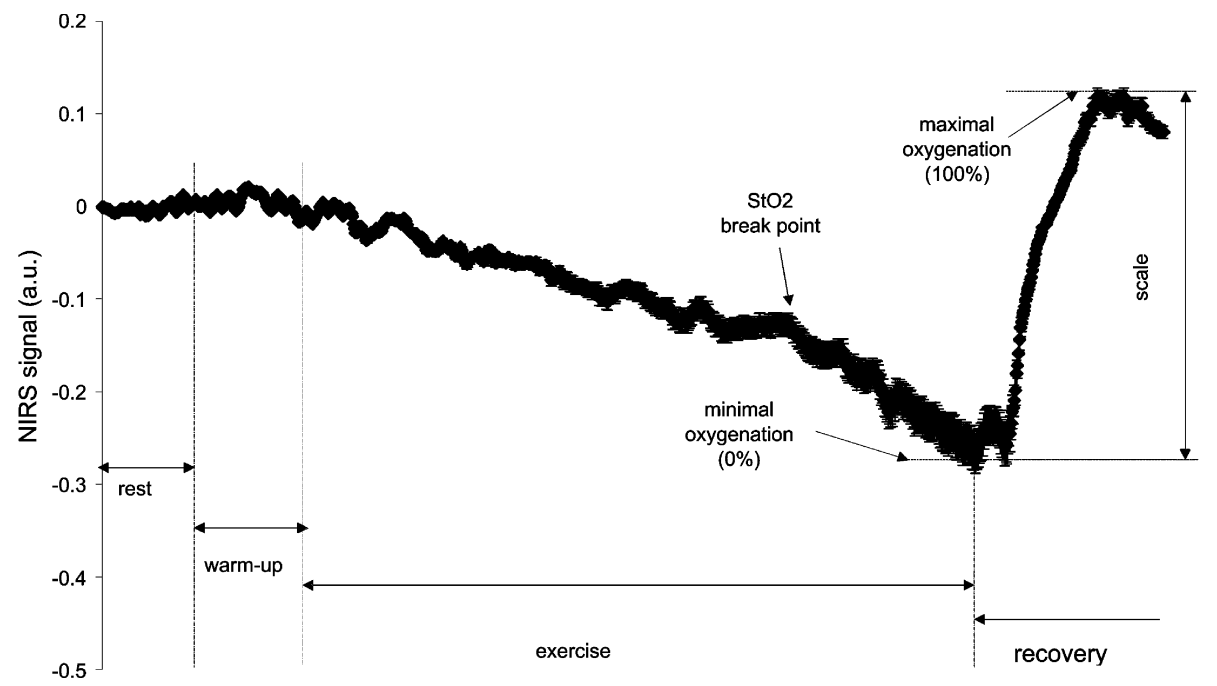

Fig. 2 Schematic representation of an NIRS measurement during incremental exercise. The values obtained between minimal $(0 \%$, end of exercise) and maximal oxygenation ( $100 \%$, hyperemia) indicate changes in muscle oxygenation during exercise. 

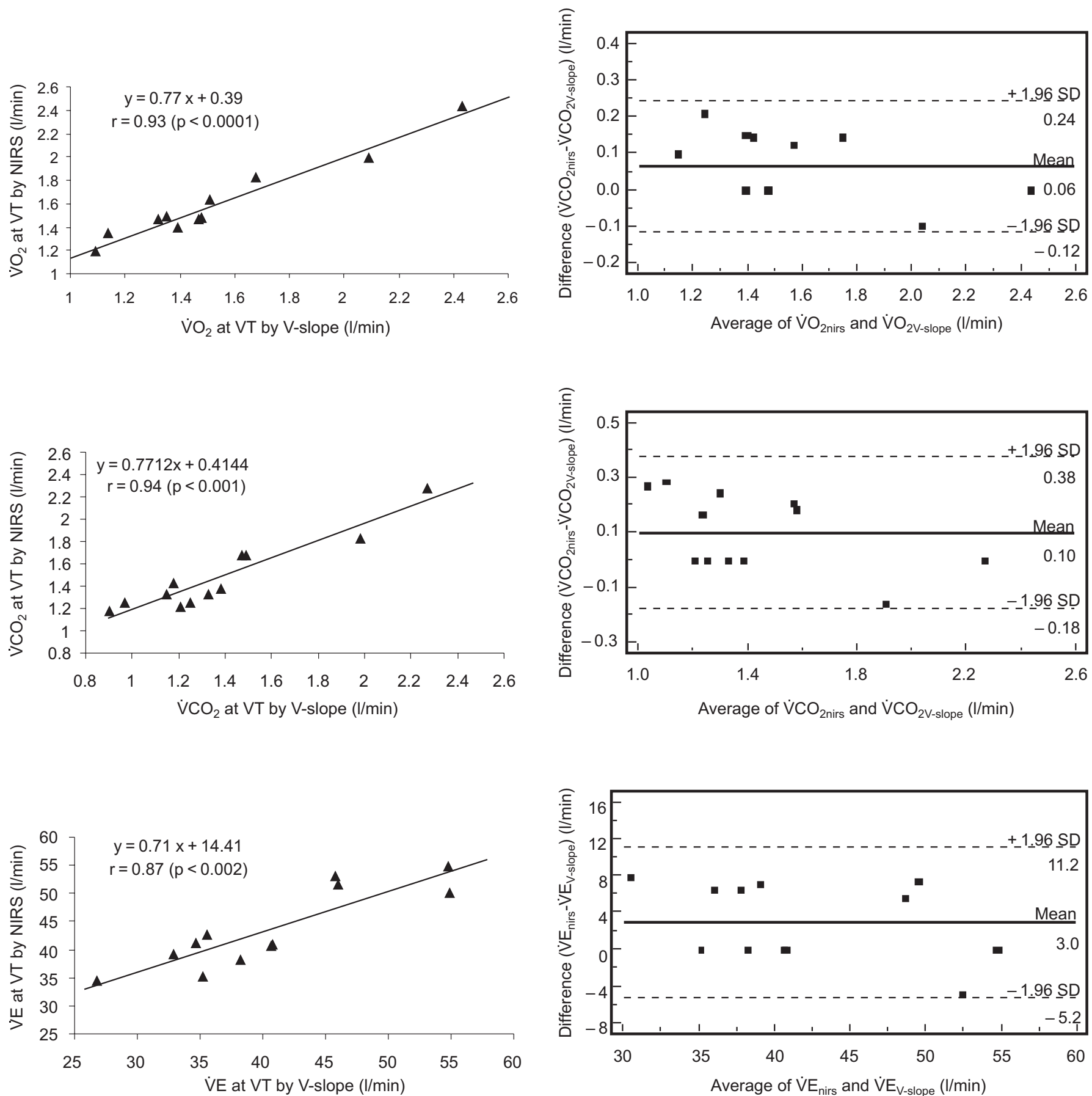

Fig. 3 Left panels contain the relationship between $V_{V-\text { slope }}$ and $V T_{\text {nirs }}$ for an entire population. Right panels show the Bland-Altman plots il-

pared to V-slope, NIRS could be used as a valid tool in the determination of VT.

During incremental exercise test, the cardiorespiratory responses at peak exercise and at VT were in agreement with the results of previous investigations within the range for similar children $[15,21,29]$. In the same way, lung function tests demonstrated normal and standard and no respiratory diseases were detected. The end point of an exercise test is greatly influenced by the motivation of the subject, particularly for children [1]. To avoid methodological interpretations of our results, two subjects were excluded because peak exercise was not reached and/or VT data were suspect.

To date, the majority of the studies evaluating tissue oxygenation by NIRS have been interested in peripheral muscles, particularly the vastus lateralis muscle $[12,13]$. In the present study, we investigated oxygenation of the respiratory muscles because their metabolism can be affected, which consequently alters exercise performance $[2,20]$. In fact, tests and measurements of respiratory muscles are not performed routinely, and development of noninvasive techniques such as occlusion pressure, tension-time index, surface electromyography (EMG), and NIRS permits a me- 
ticulous comprehension of respiratory function response and adaptation. The most important muscle of inspiration is the diaphragm but various other muscles such as intercostals, scalenes, triangularis, sternocleidomastoid, and pectoralis contribute additionally to inspiration. In the current study, we focused on an accessory inspiratory muscle, the anterior serratus, for two reasons: primarily, it is difficult to have access to the diaphragm muscle because of its anatomical arrangement; secondly, the anterior serratus muscle attach to the rib cage at an extrathoracic anchoring point, the shoulder gender. Thus, under conditions of increased ventilatory demand, this muscle plays a major role in the increase of ventilation [16]. In the literature, the term respiratory muscles are used to avoid confusion. In this sense, Gaultier [18] concluded that it is more appropriate to describe the values obtained when recording diaphragm activity by surface electrode EMG as chest wall EMG rather than diaphragmatic EMG because tracings can be contaminated by other inspiratory or expiratory muscles.

The originality of our work was the use of NIRS in the assessment of respiratory muscles oxygenation. During exercise, $\mathrm{StO}_{2}$ decreased progressively as exercise intensity increased. This result indicates a reduced oxygen transport to the respiratory muscles, which causes hypoxia [2]. The NIRS signal coming from the capillaries, arterioles, and venules, reflects the balance between local muscle oxygen delivery and muscle oxygen utilization at the site of oxygen exchange within the region of NIRS interrogation [9]. Therefore, the decreased signal shown in our study indicates a decrease in oxygenation, i.e., impaired oxygen utilization by respiratory muscles because of insufficient oxygen supply to support contractile activity. Flaminiano and Celli [16] and Jonville et al. [20] have reported that the diaphragm function depends directly on the ability of the circulation to deliver adequate oxygen and substrates. Our results agree with the findings of Mancini et al. [24] and Terekado et al. [33] who reported deoxygenation of respiratory muscles associated with greater work of breathing during exercise in normal subjects and patients with heart failure. Unfortunately, no pediatric study reported oxygenation states in children, but compared to adults, they present the same cardiovascular responses $[10,30,34]$ and the same respiratory muscle pressures [18] relative to their body size. In contrast, children are characterized by shallow and rapid pulmonary ventilation and a higher respiratory rate [21].

Detection of VT from the dynamic responses of both gas exchange and $\mathrm{StO}_{2}$ data during incremental exercise using $\mathrm{VT}_{\mathrm{V} \text {-slope }}$ and $\mathrm{VT}_{\text {nirs }}$ has shown high relationship, and significant correlation ( $r=0.87$ to 0.94 ) was found between these two methods. VT is observed when muscle oxygen requirements begin to exceed that provided, which causes as a consequence an increase in the expired $\mathrm{CO}_{2}$ generated from the bicarbonate buffering of lactic acid [36]. In our study, Fig. 1c illustrated the decrease of oxygenation and the increase of ventilation reflecting thus perfectly the mechanical load of the respiratory muscle during exercise. The correlations obtained between $\mathrm{VT}_{\mathrm{V} \text {-slope }}$ and $\mathrm{VT}_{\text {nirs }}$ indicate that the anaerobic metabolism solicitation occurs simultaneously in both respiratory muscles and peripheral muscles as a result of deoxygenation. However, Bhambhani et al. [6] have found that VT detected by NIRS in peripheral muscle (vastus lateralis) coincides with VT found by the V-slope method in adults.
The metabolism adaptation, of course, depends on oxygen, i.e., blood flow which supplies energy substrates and washes out metabolites that can impair muscle contractility [35]. Since the distribution of cardiac output during exercise to specific tissues is generally proportional to their metabolic activity, Harms [19] concluded that exercise performance may also be affected by the work of breathing during heavy exercise due to the redistribution of blood flow between the chest wall and the locomotor muscles. In the present investigation, we compared the difference in data between the V-slope and NIRS methods of VT determination, and we observed clearly a good agreement, as graphically shown in Bland-Altman plots (Fig. 3). In fact, the difference scores (expressed as mean and SD) were centered closely around zero, and all data were inside the \pm 1.96 SD fixed interval. Thus, the strong relationship between $\mathrm{VT}_{\mathrm{V} \text {-slope }}$ and $\mathrm{VT}_{\text {nirs }}$ demonstrate that NIRS permits the detection of the VT of respiratory muscles in children. Nevertheless, the difficulty of such graphical method arises when there is no clear breaking point from linearity in the curve. For this reason the visual determination of VT from the graph was considered a subjective judgment [7], but the use of experienced and independent observers excludes this hypothesis.

In summary, this study demonstrates that respiratory muscles deoxygenate during incremental exercise in children. Thus, the findings suggest that restricted oxygen delivery could contribute to the onset of anaerobic metabolism and probably fatigue of respiratory muscles. Furthermore, this investigation showed a close agreement between $\mathrm{VT}_{\mathrm{V} \text {-slope }}$ and $\mathrm{VT}_{\text {nirs }}$ and validates the use of NIRS as an additional tool for the determination of VT. In perspective it would be interesting to use VT of respiratory muscle as an index of efficiency, and as an intensity of training in healthy or patient subjects.

\section{Acknowledgements}

This work was supported by the financial assistance of "le Conseil Régional de Picardie (Pôle GBM: périnatalité - enfance)" and the European Social Fund. The authors wish to thank Dr. Rémi Gauthier and Yves Maingourd from the Department of Pediatrics Cardiopulmonary Explorations for helpful advice and support and Dr. Marie-Rose Van Calsteren for assistance with the English language.

\section{References}

${ }^{1}$ Baba R, Nagashima M, Nagano Y, Ikoma M, Nishibata K. Role of the oxygen uptake efficiency slope in evaluating exercise tolerance. Arch Dis Child 1999; 81: 73 - 75

2 Babcock MA, Johnson BD, Pegelow DF, Suman OE, Griffin D, Dempsey JA. Hypoxic effects on exercise-induced diaphragmatic fatigue in normal healthy humans. J Appl Physiol 1995; 78: 82 - 92

3 Bae S, Hamaoka T, Katsumura T, Shiga T, Ohno H, Haga S. Comparison of muscle oxygen consumption measured by near infrared continuous wave spectroscopy during supramaximal and intermittent pedaling exercise. Int J Sports Med 2000; 21: $168-174$

${ }^{4}$ Beaver WL, Wasserman K, Whipp BJ. A new method for detecting anaerobic threshold by gas exchange. J Appl Physiol 1986; 60: $2020-2027$ 
5 Belardinelli R, Barstow TJ, Porszasz J, Wasserman K. Changes in skeletal muscle oxygenation during incremental exercise measured with near infrared spectroscopy. Eur J Appl Physiol 1995; 70: 487-492

${ }^{6}$ Bhambhani YN, Buckley SM, Susaki T. Detection of ventilatory threshold using near infrared spectroscopy in men and women. Med Sci Sports Exerc 1997; 29: 402 - 409

7 Bischoff MM, Duffin J. An aid to the determination of the ventilatory threshold. Eur J Appl Physiol 1995; 71: 65-70

8 Bland JM, Altman DG. Statistical methods for assessing agreement between two methods of clinical measurement. Lancet 1986; 1: 307 310

9 Chance B, Dait T M, Chang C, Hamaoka T, Hagerman F. Recovery from exercise-induced desaturation in the quadriceps muscle of elite competitive rowers. Am J Physiol 1992; 262: 766-775

10 Cheatham CC, Mahon AD, Brown JD, Bolster DR. Cardiovascular responses during prolonged exercise at ventilatory threshold in boys and men. Med Sci Sports Exerc 2000; 32: 1080 - 1087

${ }^{11}$ Cooper DM, Weiler-Ravell D, Whipp BJ, Wasserman K. Aerobic parameters of exercise as a function of body size during growth in children. J Appl Physiol 1984; 56: 628-634

12 Costes F, Denis C, Roche F, Prieur F, Enjolras F, Barthelemy JC. Ageassociated alteration of muscle oxygenation measured by near infrared spectroscopy during exercise. Arch Physiol Biochem 1999; 107 $159-167$

${ }^{13}$ DeLorey DS, Kowalchuk JM, Paterson DH. Relationship between pulmonary $\mathrm{O}_{2}$ uptake kinetics and muscle deoxygenation during moderate-intensity exercise. J Appl Physiol 2003; 95: 113 - 120

14 Dickstein K, Barvik S, Aarsland T, Snapinn S, Karlsson J. A comparison of methodologies in detection of the anaerobic threshold. Circulation 1990; 81: $38-46$

15 Fawkner SG, Armstrong N, Potter CR, Welsman JR. Oxygen uptake kinetics in children and adults after the onset of moderate-intensity exercise. J Sports Sci 2002; 20: 319-326

16 Flaminiano LE, Celli BR. Respiratory muscle testing. Clin Chest Med $2001 ; 22: 661-677$

17 Gaskill SE, Ruby BC, Walker AJ, Sanchez OA, Serfass RC, Leon AS. Validity and reliability of combining three methods to determine ventilatory threshold. Med Sci Sports Exerc 2001; 33: 1841 - 1848

18 Gaultier C. American Thoracic Society/European Respiratory Society. Tests of respiratory muscle function in children. Am J Respir Crit Care Med 2002; 166: 601-609

${ }^{19}$ Harms CA. Effect of skeletal muscle demand on cardiovascular function. Med Sci Sports Exerc 2000; 32: 94-99

20 Jonville S, Delpech N, Denjean A. Contribution of respiratory acidosis to diaphragmatic fatigue at exercise. Eur Respir J 2002; 19: 1079 1086

${ }^{21}$ Mahon AD, Gay JA, Stolen KQ. Differentiated ratings of perceived exertion at ventilatory threshold in children and adults. Eur J Appl Physiol 1998; 18 : 115 - 120
22 Mahon AD, Marsh ML. Reliability of the rating of perceived exertion at ventilatory threshold in children. Int J Sports Med 1992; 13: 567 - 571

${ }^{23}$ Mancini D, Bolinger L, Li H, Kendrick K, Chance B, Wilson J. Validation of near-infrared spectroscopy in humans. J Appl Physiol 1994; 77: $2740-2747$

24 Mancini D, Ferraro N, Nazzaro D, Chance B, Wilson J. Respiratory muscle deoxygenation during exercise in patients with heart failure demonstrated with near-infrared spectroscopy. J Am Coll Cardiol 1991; 18: $492-498$

25 McCully K, Hamaoka T. Near-infrared spectroscopy: what can it tell us about oxygen saturation in skeletal muscle? Exerc Sport Sci Rev 2000; 28: $123-127$

${ }^{26}$ Miura H, Araki H, Matoba H, Kitagawa K. Relation among oxygenation, myoelectric activity, and lactic acid accumulation in vastus lateralis muscle during exercise with constant work rate. Int J Sports Med 2000; $21: 180-184$

27 Myers J, Ashley E. Dangerous curves. A perspective on exercise, lactate, and the anaerobic threshold. Chest 1997; 111: 787-795

28 Quanjer PH, Borsboom GJ, Brunekreef B, Zach M, Forche G, Cotes JE, Sanchis J, Paoletti P. Spirometric references values for white European children and adolescents. Polgar revisited. Pediatr Pulmonol 1995; 19: $135-142$

${ }^{29}$ Reybrouck T, Weymans M, Stijns H, Knops J, van der Hauwaert L. Ventilatory anaerobic threshold in healthy children. Age and sex differences. Eur J Appl Physiol 1985; 54: $278-284$

30 Rowland T, Popowski B, Ferrone L. Cardiac responses to maximal upright cycle exercise in healthy boys and men. Med Sci Sports Exerc 1997; 29: 1146 - 1151

31 Smith-Blair N. Mechanisms of diaphragm fatigue. AACN Clin Issues 2002; 13: $307-319$

32 Svedahl K, Macintosh BR. Anaerobic threshold: the concept and methods of measurement. Can J Appl Physiol 2003; 28: 299-323

33 Terakado S, Takeuchi T, Miura T, Sato H, Nishioka N, Fujieda Y, Kobayashi R, Ibukiyama C. Early occurrence of respiratory muscle deoxygenation assessed by near-infrared spectroscopy during leg exercise in patients with chronic heart failure. Jpn Circ J 1999; 63: 97-103

34 Vinet A, Nottin S, Lecoq AM, Obert P. Cardiovascular responses to progressive cycle exercise in healthy children and adults. Int J Sports Med 2002; 23: $242-246$

35 Ward ME, Magder SA, Hussain SN. Oxygen delivery-independent effect of blood flow on diaphragm fatigue. Am Rev Respir Dis 1992; 145: 1058 - 1063

36 Wasserman K, Beaver WL, Whipp BJ. Gas exchange theory and the lactic acidosis (anaerobic) threshold. Circulation 1990; 81: 14-30

37 Wasserman K, Hansen JE, Sue DY, Casaburi R, Whipp BJ. Principles of Exercise Testing and Interpretation. 3rd ed. Baltimore, Philadelphia: Lippincott Williams \& Wilkins, 1999 